\title{
making things visible
}

\author{
Dianne Reid
}

W

hen I first picked up a video camera and began looking at the dancing body, it was driven by a desire to stop the body from disappearing, to give it actuality and, in doing so, to bestow value and worth. By getting close enough and approaching from different angles it became possible to surprise the body, to uncover the invisible and to open the possibilities - that we are more than this flesh cage, this architecture, which is making and unmaking itself every moment.

The more I hold the camera the more it becomes flesh, this frame an extension of my own body, dancing in duet with subject/landscape. Now my desire is to undo it, dismantle it, reveal its process of un-becoming. I want to make the process visible and, in doing so, keep subjectivity alive.

I carried Pia's essay, "Falling into the Surface," around with me for several days before reading it and during that time used the reverse side to record notes from my improvisational performance practice. As I finally got to reading and then turning each of her pages, my eyes passed over fragments of my own notes and began to make connections: how thoughts on improvisational practice connect to these notions of virtual architecture. The undoing and evolution possible in architecture suggested by Pia echoes the observation that in improvisation "the world is constantly being disrupted and something is coming up as a result."1

As an improviser, with or without camera, I am engaging in the present moment, paying attention - to my breath, to the moment when breath becomes sound, to what a movement uncovers, to sensation, to what distracts me. Now, as I read I am noticing the juxtaposition of not just two pieces of writing, but also of my body and the buildings I move through. I am considering the potential of my breath to permeate their surfaces and for their particles to move through me. I am enjoying the idea that structures can be fluid and that the poetic intersects with the academic.

My work is mostly concerned with moments, with time. Time is the process of our body's architecture. The vertical plane, the standing body, is said to represent the infinitethe present moment at once all that exists and that which is continually disappearing. This body you touch/see now is virtual. A lifetime could be mapped as a series of virtualities, the actual as a shifting point along its journey. Like a flick book, the picture is only constructed through the disruption of the fixed, the collision of pages into a compressed timeframe, connecting the pieces through an illusion of shared space.

Connections can be drawn between the forms of dance and architecture. Each term refers to both process and product in the construction of each respective form. They are dealing with physical structures that house, protect and enable human expression. They are re-shaped by cultural and technological change. A skyscraper is a cold hard object on a fixed foundation adhering to rules of geometry to work with and in spite of the forces of 
gravity. My dancing body, my practice, began that way. I had to begin with a syllabus, rules and disciplines in order to work against (at first) and with (later) the forces of gravity and negotiating the other structures (bodies and walls/objects) around me. The technology I have negotiated has moved from the hard edges of the pointe shoe to the virtual edge of software/wear/where. There is a political and spiritual metaphor at play in these notions of structures of control and order and the possibility of the unknown. There is also a discussion about artistic practice, as an imaginative space, as a means to test and extend the possibilities of science and technology.

\section{falling apart}

My recent artistic practice is an example of this idea of evolution being a kind of falling apart. When I began as a dance filmmaker, I was trying to create a subjectivity, to make actual/visible the virtual/intangible. I was building a new structure, a new dance, with these new tools and trying to make this new object (a hard plastic case surrounding spools of magnetic tape) fluid and organic like a human body. As my practice evolves it now becomes about deconstructing the process and, in doing so, enabling new ways to see dance and the body.

For A Broken Puzzle with Weave Movement Theatre (2010), I worked with multiple unknowns, with a dozen very different bodies and minds. These dancers' bodies, their physical and mental architectures, are off-balance, asymmetrical, unpredictable, and spontaneous. Physical spasms are norms, so the explosive unknown is a "virtuality" - that is, an unseen phenomenon that can engage with the actual at any moment. These bodies really fall and the impact is felt, so I must create processes to survive the unknown, negotiate the action. I want to bring the camera into an intimate range, to magnify each individual's physical differences and celebrate their uniqueness. The gaze of the viewer can be controlled and informed by the movement and proximity of the camera. By approaching the subject with the curiosity of a child, that is, a desire to know and experience the new and different, I believe I can create a shared space where other types of bodies and possibilities for movement exist. In coming so close to these different bodies'surfaces, I am inviting the viewer to look beyond the surface metaphorically, to "become sensitive" and "have a perception of an otherwise relatively latent presence."2 I am aiming for a de-mystification of disability that shows the might of a crumbling structure, the credibility of collapse, the delicacy of distortion.

To do this I must consider context to uncover content, design movement scores to access what lies beneath the surface and give each individual a palate of physical and imaginative material to work with.

Verbally recall sensations from a personal journey/memory

Physically respond to these lines of text:

1. Come to a place outside of time, beyond geography

2. Count your bones

3. Hear the light

4. Ghost fingers/invisible touch

5. Lie like a broken puzzle ${ }^{3}$ 
To capture the footage I must create a moving structure that is undoing/revealing for the camera. Keeping the performers' subjectivity alive means giving space and duration to the possibilities of connection, privileging the process of moving between modes of seeing and being seen. We become cameras and viewers simultaneously, actively engaged in constructing the event we are inside. It is a tiny shift in perception rather than action that determines whether we are a participant in the dance or an observer in the same space.

\section{Location and watching}

Position yourself somewhere in relation to what you see, notice what you see from that angle, that proximity, notice what is in the background, what frame are you looking through, notice the quality of the light, the texture of the surface you are connected to, the temperature, the sounds... keep shifting your focus from the close up to the distance... move between watching and becoming part of what you are watching... ${ }^{4}$

... so our edges become blurred and viscous and our attention is alive and real ... the possibilities, the virtualities, falling into one another's surfaces, each becoming actual through the process of another's perception.

In the editing of the dance film, alone in the edit suite, it is my point of view that is privileged, but I want to imbue fluidity into what will be a fixed architecture, in some way to continue to relinquish control, insert chaos into the order. So I create a soundtrack from the cutting up and distorting of their voices and body sounds. I will assemble the visual architecture on this virtual blueprint; create a form that reconfigures gravity and narrative; build a structure that is always falling, is on the edge of collapse, and exists in a different plane.

Slowing, reversing, cutting and repeating words and sounds-occasionally a whole sentence to lead us down a corridor, to put walls around the pathway.

pause... approach, depart... diesel, half awake, shhh, a touch ... two, and, dark, splash, I saw the sea reflected in my grandmother's eyes...

I taste the smell of forgotten passengers, vibrating rattles my spine, my hand, refreshingly minty ${ }^{5}$

\section{And this construct becomes a metaphor for "difference"...}

Being continually made, cut free from temporality, surfaces are felt and merging into each other ... so "the subjective is not originated in an individual, rather it is produced through the transitory assemblages of a vast array of impersonal forces." ${ }^{\prime \prime}$

And the viewers can become aware of being watched, to be within the action as they make sense of where they are at each moment. The complete form is not visible, the bodies are strange, the stories are personal and fragmented ... the viewer is inside someone else's head, watching, falling ... the only constant is perpetual change.

Our bodies are continually metamorphosing. The skeleton is alive and changing, renewing itself in less than two years, the skin renews itself every month.' Our actualities are in motion. In their flux, all our surfaces are virtually the same. 


\section{A broken puzzle}

I am split by your scrutiny

Fractured by your fascination

Dismantled by your deliberations

I am this piece of blue sky, that dark corner,

A disembodied limb, an upturned cart, a winter branch,

Pieces of possibility discarded by a sideways glance. ${ }^{8}$

\section{References}

Ednie-Brown, Pia. "Falling into the surface (toward a materiality of affect)." Hypersurface Architecture II .

Architectural Design Academy Editions 69 (1999): 1-12.

Morrish, Andrew. Coaching in Performance Improvisation. Cecil Street Studio, Fitzroy, Melbourne, November 9-12,2010.

Reid, Dianne. Rehearsal notes for A Broken Puzzle. Melbourne, August-September 2010.

Tufnell, Miranda and Chris Crickmay. Body, Space, Image: notes towards improvisation and performance. Great Britain: Dance Books, 1990.

Weave Movement Theatre. "A Broken Puzzle." Program notes presented at the Melbourne Fringe Performance of Weave Movement Theatre, Brunswick, September 24-26, 2010. http://weavemovementtheatre.com.au/.

\section{Notes}

1. Reid, "Rehearsal Notes."

2. Ednie-Brown, "Falling," 10.

3. Reid, "Rehearsal Notes."

4. Ibid.

5. Ibid.

6. Ednie-Brown,"Falling," 9.

7. Tufnell and Crickmay, “Body, Space, Image," 3.

8. Weave, "A Broken Puzzle." 